\title{
12 Hylomorphism and the New Mechanist Philosophy in Biology, Neuroscience, and Psychology
}

\author{
Daniel D. De Haan
}

\begin{abstract}
Scholasticism did not know how to draw from its principles the physics which could and should flow from them. So our first duty today is to be more faithful to the demands of realism than the Middle-Ages were, and giving each order of reality its due. In each order, the reality of the form should be preserved, since without it one cannot account for structures, and it remains the principle of reality's intelligibility.
\end{abstract}

Etienne Gilson, Methodical Realism, 103

Many philosophers and scientists believe that the turn to mechanistic explanations in the seventeenth century dealt the final death blow to Aristotelian hylomorphism. ${ }^{1}$ While this might be the correct interpretation of the historical shift from hylomorphic to mechanistic explanations, in this essay I argue that contemporary versions of Aristotelian hylomorphism and the "new mechanist philosophy" in biology, neuroscience, and psychology share significant commitments about the reality of the organized causal components of mechanisms. My aim is to challenge the well-known narrative that hylomorphic and mechanistic ontologies are fundamentally incompatible by establishing that the new mechanist philosophy and Neo-Aristotelian hylomorphism are not only complementary, but are defending many of the same ontological claims.

I begin with a brief sketch of the fundamental claims of hylomorphism $(\$ 1)$. I then situate the new mechanist philosophy $(N M P)$ within recent developments in philosophy of science $(\$ 2.1)$, before introducing the basic framework of NMP $(\$ 2.2)$. In the last two sections of the paper I argue for the compatibility of hylomorphism and NMP. I start with the major points of agreement between hylomorphism and NMP (\$3). Significantly, I establish that NMP is committed to organization or structure realism (a touchstone of hylomorphism), and Neo-Aristotelian hylomorphism is committed to the reality of mechanisms or causal powers that produce, underlie, or maintain the behavior or capacity of (i) phenomena that are constituted through the (ii) spatial, temporal, and active organization of their (iii) component entities and (iv) component activities (the four hallmarks of NMP). In the last section 
$(\$ 4)$ I introduce some possible points of disagreement between these two positions pertaining to hylomorphism's substance-attribute ontology, emergence, downward causation, and teleology. I show that the disagreements about these topics do not distinguish hylomorphists from new mechanists, but represent disagreements among hylomorphists and among new mechanists. I conclude that Neo-Aristotelian hylomorphism should not been seen as fundamentally opposed to mechanisms, but that it can and should embrace the many complementary features of the new mechanist philosophy in biology, neuroscience and psychology. If correct, this is a significant advance over and against an influential narrative that should be rejected.

I begin with a few preliminary points of clarification for this comparative study. My principal aim is to encourage a constructive conversation between hylomorphists and new mechanists. I therefore intentionally avoid trying to settle significant points of disagreement among hylomorphists or new mechanists that would prematurely alienate some hylomorphists from some new mechanists (and vice versa) on issues that I believe are not pertinent to the compatibility of hylomorphism and the new mechanist philosophy. My presentation of both hylomorphism and NMP focuses more on the fundamental principles that unite rather than divide hylomorphists under a common banner, and that bring together the diverse views of exponents of NMP. Finally, in order to achieve a synoptic comparison of these two complex and nuanced philosophical frameworks, my exposition forgoes many of the arguments for and against particular positions maintained by hylomorphists and the new mechanists.

\section{Neo-Aristotelian Hylomorphism}

Hylomorphism originates with Aristotle's philosophy of nature and takes its name from his account of matter (byle) and form (morphe), that is, the two integrated and intrinsic principles or grounds for all physical substances. Aristotle's doctrine of hylomorphism is worked out alongside his account of physical substances, attributes, forms of natural change and composition, act and potency, the four causes (material, formal, agential, and final), the distinction between inanimate and animate beings, and his application of these positions throughout his philosophical biology and zoology. Contemporary exponents of hylomorphism often introduce it as a "third way" alternative to substance dualism and various forms of eliminative, reductive, and non-reductive physicalism.

\subsection{Hylomorphism's Organization Realism}

Contemporary hylomorphism is often characterized by its realist account of higher-levels of what is variously called "form," "organization," or "structure" and causal powers. William Jaworski, a contemporary exponent of hylomorphism, argues that the fundamental distinguishing feature 
of hylomorphism is its structure realism-I call this form or organization realism. Following Jaworski, we can sum up this insight about formal organization in the following slogans:

Formal organization matters: it operates as an irreducible ontological principle, one that accounts at least in part for what things essentially are.

Formal organization makes a difference: it operates as an irreducible explanatory principle, one that accounts at least in part for what things can do, the powers they have.

Formal organization counts: it explains the unity of composite things, including the persistence of one and the same living individual through the dynamic influx and efflux of matter and energy that characterize many of its interactions with the wider world. ${ }^{2}$

The formal organization realism defended by hylomorphists like Jaworski, Robert Koons, David Oderberg, Anna Marmodoro, Bernard Lonergan, and others distinguish form from the mere static spatial relation of parts to each other. $^{3}$ For hylomorphism, form, organization, or structure is a dynamic intrinsic ordering principle of the organized materials, especially in the case of the organizational form of living beings. As Oderberg points out:

$[\mathrm{M}]$ ere structure in the sense of configuration of parts is far too static a concept to tell you all there is about the form of an animal: There are its characteristic functions and behaviour, its dispositions, instincts, tendencies, actions and reactions, and all the rest of which ethology is made. These dynamic notions have to be added to the relatively static structural notions to get us to something like an account of the form of a living thing. ${ }^{4}$

Aristotelian hylomorphism maintains that organization is not an additional part standing alongside material components that provides a relation of unity to material parts; furthermore, form is not a mere extrinsic organization imposed on material parts from an extrinsic (efficient) cause; rather, formal organization intrinsically transforms the matter, thereby constituting a new unity, identity, whole. ${ }^{5}$

\subsection{Hylomorphism's Substance-Attribute Ontology}

This brings us to hylomorphism's connection to Aristotle's substanceattribute ontology. Hylomorphists distinguish between two kinds of organization: what many Neo-Aristotelians call substantial and accidental forms, what Jaworski calls individual-making and activity-making structures, and what Bernard Lonergan identifies as central and conjugate forms. ${ }^{6}$ I employ Lonergan's terminology of central and conjugate formal organization to articulate the main contentions of hylomorphism. ${ }^{7}$ A central form is 
a fundamental intrinsic principle that actually organizes and transforms the materials that compose a fundamental physical entity, that is, a substance. Hylomorphists maintain that the central forms of physical substances are essentially and continuously organizing and transforming the material components that constitute the substance, and it is this organizing activity of central forms that unifies and enables the same physical substances to persist through changes in their materials. ${ }^{8}$ The same is true, mutatis mutandis, of conjugate forms, which organize the constituent materials of a substance's powers and activities. Following Jaworski, we can also frame three slogans that capture what is specific to conjugate forms.

Conjugate formal organization matters: it is an irreducible ontological principle that organized activities possess essentially and which, in part, accounts for the very nature of what the activities are that they organize.

Conjugate formal organization makes a difference: because it is the form of a power which provides an irreducible explanatory principle; and powers enable individuals to engage in organized activities they could not perform without such powers.

Conjugate formal organization counts: it confers unity on diverse events in a way that is similar to how substantial forms confer unity on physical materials that compose organized individual substances. ${ }^{9}$

In addition, conjugate formal organization also minds: sensation, perception, affectivity, understanding, rational reflection, and intentional action are species of organized activities of psychological powers. The psychological powers and activities of humans and other animals are composed from the formal organization of their material parts and the manifestation of any requisite powers of the organized materials in the surrounding environment. Animals have the psychosomatic powers and operations they do in virtue of the organization of specific zones of their material parts by their conjugate forms. ${ }^{10}$

The central and conjugate forms of a substance are bound up with its fundamental central matter and organized conjugate potencies. The former is what is actualized and organized by a substance's central form, the latter pertains to zones of organized material components that are constituted by the conjugate forms of an individual substance. Accordingly, there are formal and material properties that pertain both to substances and to their conjugate attributes.

\subsection{Staunch Hylomorphism: Fundamental Entities, Properties, and Powers}

Hylomorphism's account of central and conjugate forms is connected to Rob Koons's division of contemporary proponents of hylomorphism into fainthearted and staunch hylomorphists. ${ }^{11}$ According to Koons, staunch hylomorphists accept the following Aristotelian claims, whereas faint-hearted 
hylomorphists deny one or more. ${ }^{12}$ I am only concerned with staunch hylomorphism.

(1) A sparse theory of fundamental entities. A soul is a substantial form, and only substances have substantial forms. Socrates is a substance, but sitting Socrates is only an accidental unity, and so there is no substantial form corresponding to Socrates's sitting as there is to Socrates's living.

(2) A sparse theory of fundamental properties. Only substances have essences or natures in the strictest sense. An essence or nature is a fundamental property, which accounts for both the possibility and actuality of all other properties, acting as a 'principle' (arche) of motion (change) and rest.

(3) A powers ontology. The natures of substances confer fundamental causal powers on those substances, and those powers (both active and passive) are the ultimate grounds for explaining all change and activity. ${ }^{13}$

Claims (1) and (2) pertain to the nature of substances and their substantial or central form and matter; claim (3) concerns the powers that are conjugate attributes of a substance.

Along with an armament of classical and contemporary arguments for its organization realism, hylomorphism defends an anti-reductionist naturalist ontology that draws upon empirical science, especially the life sciences, to fortify and support its position. Indeed, some hylomorphists, like Jaworski, even cite proponents of NMP, like Carl Craver and William Bechtel, to provide empirical support for hylomorphism's ontological realism.

Hylomorphism is committed to ontological naturalism, the claim that when it comes to determining what exists, empirical investigation is our best guide. Since many of our best empirical descriptions, explanations, and methods appear to posit various kinds of organization or structure, those descriptions, explanations, and methods give us prima facie reason to think that organization or structure exists. Structure realism takes empirical appeals to structure at face value. Structure, it says, is a basic ontological and explanatory principle: descriptions, explanations, and methods that posit structure cannot in general be reduced to, or paraphrased, or eliminated in favor of nonstructural descriptions and explanations. This straightforward approach to structure is the one favored by hylomorphists. ${ }^{14}$

\section{New Mechanist Philosophy}

\subsection{The Rise of the New Mechanists in the Philosophy of Science}

The new mechanist philosophy represents a more recent movement in philosophy of science; it is tied to a number of positions in philosophy of science that began to coalesce around the end of the twentieth century as a reaction 
to logical empiricism. In contrast to logical empiricism's focus on logical and mathematical idealizations of the theories of physics, NMP attends more to actual scientific practice, especially among the special sciences of biology, neuroscience, and psychology. "Many new mechanists developed their framework explicitly as a successor to logical empiricist treatments of causation, levels, explanation, laws of nature, reduction, and discovery." 15 While the discovery of mechanisms has always been important to scientists, mechanisms were neglected in twentieth-century philosophy of science due to the overwhelming influence of logical empiricism's covering-law account of explanations, like the deductive-nomological model. Against the framework of logical empiricism, more recent philosophers of science have argued that scientific explanations of a phenomenon, especially outside of physics, do not consist in showing that a phenomenon was predictable on the basis of laws of nature or other generalizations. Carl Craver argues that neuroscientists are instead interested in "showing how a phenomenon is produced by its causes. To explain neurotransmitter release, one shows that the depolarization opens the $\mathrm{Ca}^{2+}$ channels, that opening the $\mathrm{Ca}^{2+}$ channels allows $\mathrm{Ca}^{2+}$ to diffuse into the cell, that vesicles dock to the membrane by forming SNARE complexes and that the influx of $\mathrm{Ca}^{2+}$ triggers the formation of a fusion pore." 16 Robert Cummins argues that psychology is not concerned with discovering explanatory laws. Following his detailed survey of the major explanatory frameworks employed in empirical psychology (belief-desire-intention folk psychology, computationalism, connectionism, neuroscience, and evolutionary psychology), he concludes:

Explanation in psychology, like scientific explanation generally, is not subsumption under law. Such laws as there are in psychology are specifications of effects. As such, they do not explain anything but themselves require explanation. Moreover, though important, the phenomena we typically call effects are incidental to the primary explananda of psychology, viz., capacities. Capacities, unlike their associated incidental effects, seldom require discovery, though their precise specification can be nontrivial. The search for laws in psychology is therefore the search for explananda, for it is either the search for an adequate specification of a capacity or for some capacity's associated incidental effects. Laws tell us what the mind does, not how it does it. We want to know how the mind works, not just what it does. ${ }^{17}$

The consolidation of these ideas and others culminated in a new orientation in philosophy of science that focused on the role of multi-level mechanisms in scientific explanation. In their seminal paper "Thinking about Mechanisms," Peter Machamer, Lindley Darden, and Carl Craver (MDC), begin with the following claim:

In many fields of science what is taken to be a satisfactory explanation requires providing a description of a mechanism. So it is not surprising 
that much of the practice of science can be understood in terms of the discovery and description of mechanisms. ${ }^{18}$

For NMP, "this new sense of mechanism is deeply anti-reductionist; science may uncover explanatory or ontological connections between higher and lower levels, but does not thereby either eliminate or reduce the higher levels thus connected." ${ }^{19}$ Craver contends that the new mechanist approach to neuroscience supports what he calls the mosaic unity of neuroscience.

This mosaic view of the unity of neuroscience is broader in scope than reduction because it covers both the integration of fields in research at a given level and in research that crosses levels. This mosaic view also provides a more accurate and elaborate view of interlevel interfield integration. Where reductionists understand the unity of science in terms of stepwise reduction to lowest levels, the mosaic view treats the unity of science as the collaborative accumulation of constraints at multiple levels. Whereas reduction focuses on relations of identity, supervenience, and ontological reductive links, the mechanistic mosaic view emphasizes the importance of explanatory relevance as the bridge between levels. Finally, whereas reduction models emphasize the importance of explanatory reduction to fundamental levels, the mosaic view can be pluralistic about levels, recognizing the genuine importance of higher-level causes and explanations. The mosaic unity of science is constructed during the process of collaboration by different fields in the search for multilevel mechanisms. One task for the philosophy of neuroscience is to show how that research ought to proceed. ${ }^{20}$

Many proponents of NMP, influenced by Wesley Salmon's account of causal explanations, are also committed to an ontic conception of scientific explanation, where mechanistic explanations pick out realties that are causal structures in the world. ${ }^{21}$ Craver distinguishes four distinct but related senses of explanation employed by English speakers. It can be used "(1) to refer to a communicative act, (2) to refer to a cause or a factor that is otherwise responsible for a phenomenon (the ontic reading), (3) to refer to a text that communicates explanatory information, and (4) to refer to a cognitive act of bringing a representation to bear upon some mysterious phenomenon." 22 Craver recognizes that scientists use explanation in all these senses; his contention is that, contrary to certain anti-realist views in philosophy of science, it is not only perfectly legitimate, but even necessary for scientists to make use of the second sense of explanations that depend upon and are evaluated in light of the ontic structure of the world..$^{23}$ Indeed, "the norms of scientific explanation fall out of a prior commitment on the part of scientific investigators to describe the relevant ontic structures in the world." 24 If Craver is correct, then we have good reasons for taking seriously the underlying realism of certain ontic explanations in biology and neuroscience 
that provide accounts (even if inadequate) of the real or ontic structure of the world-especially those that appeal to mechanisms constituted by organized causal components. I shall not enter into the debates over Craver's complex and contentious defense of ontic explanations. ${ }^{25}$ Nonetheless, it is worth pointing out that his defense of scientific realism about ontic explanations and structures found in nature provides one more point of agreement between hylomorphism and some proponents of NMP.

\subsection{New Mechanists on Mechanisms}

There have been many conceptions of mechanisms throughout the history of philosophy and science, but NMP places some distance between its understanding of mechanisms from the conceptions of mechanisms of Democritus, Descartes, Boyle, and others. NMP does not endorse the metaphysically austere accounts of the natural world defended by Cartesianism or more recent ontologies that endeavor to reduce all causal activities to a few fundamental forces. Unlike many accounts of mechanisms, NMP resists the idea that mechanisms are machines or are straightforwardly analogous to them. ${ }^{26}$ Furthermore, according to Craver and other proponents of NMP, mechanisms are not essentially: deterministic (many are stochastic), reductionistic (most require multilevel irreducible ontic structures), localizable (many brain mechanisms are highly distributed), and are not mere fictions, metaphors, or explanatory heuristics (but describe and explain ontic structures in the world). So what are mechanisms, according to NMP?

NMP prefers qualitative accounts of the explanatory mechanisms actually employed by scientists over retailing their necessary and sufficient conditions. ${ }^{27} \mathrm{~A}$ number of accounts of mechanisms are on offer from different proponents of NMP.

Mechanisms are entities and activities organized such that they are productive of regular changes from start or set-up to finish or termination conditions..$^{28}$

A mechanism is a structure performing a function in virtue of its component parts, component operations, and their organization. The orchestrated functioning of the mechanism is responsible for one or more phenomena. ${ }^{29}$

Mechanisms are entities and activities organized such that they exhibit the explanandum phenomenon. ${ }^{30}$

Minimal mechanism: A mechanism for a phenomenon consists of entities (or parts) whose activities and interactions are organized so as to be responsible for the phenomenon. ${ }^{31}$

In what follows, I draw on the work of the philosopher of neuroscience, Carl Craver, and other exponents of NMP to summarize the basic claims of NMP. Craver presents a detailed account of mechanistic explanations used 
in neuroscience in his 2007 monograph, Explaining the Brain: Mechanisms and the Mosaic Unity of Neuroscience and in his 2013 In Search of Mechanisms: Discoveries Across the Life Sciences co-authored with Lindley Darden. Craver contends that "Explanations in neuroscience describe mechanisms, span multiple levels, and integrate multiple fields." 32 In other words, neuroscientific explanations appeal to mechanisms that encompass a complex hierarchy of organized component entities and activities that require the integration of such scientific fields as biochemistry, genetics, microbiology, electrophysiology, neurobiology, neuroscience, neuropsychology, and many others. ${ }^{33}$ Craver's account of a mechanism draws attention to four fundamental elements: (1) a phenomenon, (2) its component entities, (3) component activities, and (4) the organization of these components.

\subsubsection{Phenomena of Mechanisms}

A phenomenon is variously described as the behavior or the manifestations of a capacity or power of the mechanism taken as a whole. The proper demarcation of a phenomenon depends in part on the level of investigation relevant to one's descriptive and explanatory goals: what counts as a phenomenon for the biochemist might be a component in a mechanism for the microbiologist, what is a phenomenon to be explained by a mechanism for the microbiologist, might be a component within a mechanism for the neuroscientist, and so on. ${ }^{34}$ In every case, the phenomenon is the behavior of the mechanism as a whole: the mechanism for protein synthesis synthesizes proteins; the mechanism for an action potential generates an action potential, and a mechanism for opening ion channels causes ion channels to open. For NMP, phenomena are not adequately described as mere inputoutput relations, even though mechanisms often do involve many inputs and outputs. Some mechanisms operate in a linear causal process from one stage to the next, but many more operate in cycles (like the Krebs cycle) and feedback loops. Phenomena can range from being products of productive mechanisms, to being systems dependent on underling mechanisms, or systems that are sustained by maintenance mechanisms. Roughly speaking, mechanisms explain how organized entities and activities (i) produce, (ii) underlie, or (iii) maintain some phenomenon. ${ }^{35}$

(i) Productive mechanisms typically consist in a causal sequence and often explain some terminating end-product. The phenomenon explained by a mechanism in the case of protein synthesis is an end-state: the production of a protein. ${ }^{36}$ Other products of mechanisms include activities and events, like digestion. (ii) Some mechanisms do not produce but underlie phenomena, such as the capacity or behavior of a whole system that is educed from the organized interactions of its implementing components. For instance, the underlying mechanism of an action potential does not produce it. The mechanism that underlies a neuron's action potential-the rapid depolarization and repolarization of the neuronal membrane that implements the electrical 
potential charge and communicates it down the neuron's axon-involves the whole neuron and the activities of its component parts such as membranes, neurotransmitters, ion channels, and ions. "This mechanism involves the choreographed opening and closing of sodium- and potassium-channel proteins and the diffusion of ions across the nerve cell's membrane." 37 (iii) Mechanisms also maintain phenomena, like regulatory or homeostatic mechanisms, which preserve a stable equilibrium among certain properties or relationships within a system in response to the alteration of internal or external conditions. For instance, "cells have mechanisms to maintain concentrations of metabolites, cardiovascular systems have mechanisms to maintain stable blood pressure, or warm-blooded animals have mechanisms to maintain constant body temperature." 38

Another feature of mechanisms flagged by NMP is regularity. A mechanism is regular if it operates "always or for the most part in the same ways under the same conditions." 39 This classic Aristotelian adage does not exclude some mechanisms from being a one-off, such as mechanisms that initiate an epidemic or speciation. NMP also distinguishes the regularity of mechanisms from determinism. "Determinism is only the limit of regularity in most biological mechanisms." Many mechanisms, especially biological ones, are not deterministic but stochastic where indistinguishable conditions, at least for us, can have very different results. "For example, when the action potential arrives at the axon terminal, one, two, or more quanta of neurotransmitters may be released, or none at all. One can generate frequencies at which each of the outcomes will occur, but one cannot predict with certainty on this basis just which outcome will be in a particular case." 40

\subsubsection{Components of Mechanisms: Entities and Activities}

NMP distinguishes the entities, activities, and organizational features of mechanisms. Entities and their activities or operations constitute the two kinds of component parts of a mechanism. Proponents of NMP disagree among themselves about which mereological account of parthood best captures the wide range of organized components that constitute a mechanism, especially for the diversity of parts present in biological mechanisms. Similarly, there are various views about how to characterize the causation of causal mechanisms. According to Craver, the ongoing NMP debate over causal mechanisms has focused on four different accounts of causation: conserved quantity accounts, mechanistic accounts, activity accounts, and counterfactual accounts. It remains an open question which, if any of these accounts, will persevere among proponents of NMP. In the absence of space, I shall not enter into this debate. ${ }^{41}$ Despite such disagreements over these details, Craver identifies a few points of agreement among proponents of NMP on causality.

New mechanists have in general been at pains both (1) to liberate the relevant causal notion from any overly austere view that restricts 
causation to only a small class of phenomena (such as collisions, attraction/repulsion, or energy conservation), and (2) to distance themselves from the Humean, regularist conception of causation common among logical empiricists. ${ }^{42}$

For NMP, entities are component parts of mechanisms that interact with other entities through their reciprocal activities. A mechanistic explanation in neuroscience, for instance:

includes various entities ( $\mathrm{N}$-type $\mathrm{Ca} 2+$ channels, $\mathrm{Ca} 2+$ ions, active zones, a host of intracellular molecules such as Rab3A, Rab3C, VAMP/ synaptobrevin, SNAP-25, and syntaxin, vesicles containing neurotransmitters, fusion pores, and neural membranes) and their various activities (opening, clamping, diffusing, docking, fusing, incorporating, phosphorylating, and priming). ${ }^{43}$

Activities induce causal changes in entities with the properties exigent for various actions or passions. "Activities are the producers of change. They are constitutive of the transformations that yield new states of affairs or new products. Reference to activities is motivated by ontic, descriptive, and epistemological concerns." ${ }^{44}$ For example, a neurotransmitter and its post-synaptic receptor are two entities that are able to engage in a reciprocal activity of binding by virtue of such properties as their structure and charge distributions. Entities have properties like location, size, structure, duration, and orientation; they typically have masses, carry charges, and transmit momentum. ${ }^{45}$ Enzymes, neurotransmitters, neurons, organs, and organisms are all entities that engage in activities-the causal components of mechanisms-including:

productive behaviors (such as opening), causal interactions (such as attracting), omissions (as occurs in cases of inhibition), preventions (such as blocking), and so on. In saying that activities are productive, I mean that they are not mere correlations, that they are not mere temporal sequences, and, most fundamentally, that they can potentially be exploited for the purposes of manipulation and control ... There are many kinds of activity, and it is the task of science rather than philosophy to sort them out. The mechanism of neurotransmitter release includes different forms of chemical bonding, conformation changes, diffusion, attraction and repulsion. ${ }^{46}$

Activities are individuated by their spatiotemporal location, rate, duration, the kinds of reciprocal entities and properties required for such activities, their setup, start and terminating conditions, modes of signaling (via autocrine, juxtacrine, paracrine, endocrine signaling), range, and energy requirements. ${ }^{47}$ 


\subsubsection{Organization of Mechanisms}

NMP unequivocally draws attention to the ontic organization of component parts-entities and activities-of mechanisms. The mechanisms that underlie an action potential are, for instance:

organized together spatially, temporally, causally, and hierarchically such that transmitters are released when the axon terminal depolarizes. The voltage-sensitive ion channels are located in the terminal, they span the membrane, and they open to expose a channel. Biochemical cascades in the cytoplasm have sequences or cycles of interactions, they are organized in series and in parallel, and their steps have different orders, rates and durations. The components in the mechanism often stand in mechanism/component relations, a species of part-whole relation. As a result the mechanism is hierarchically organized. The behavior of the mechanism as a whole requires the organization of its components. ${ }^{48}$

The component parts of a mechanism are organized spatially, temporally, and actively, and this organization makes a difference to the mechanism as a whole. Spatial organization consists in locations, sizes, shapes, positions and orientations of component entities; temporal organization pertains to the orders, rates, and durations of entities and their activities. Active organization comprises the diverse ways the properties of components-entities and activities-enable components to make a difference to other components.

Active organization distinguishes mechanisms from mere aggregates (or heaps) of matter, such as piles of sand. The parts act and interact with one another in such a way that the whole is literally not a mere sum of its parts. Mechanisms are in this sense nonaggregative: the parts of the mechanism are organized in ways that go beyond, e.g., the contribution made by the mass of a grain of sand to the mass of the pile. Mechanisms are not mere sums of properties of their component parts . . . ${ }^{49}$

The active organization of a mechanism's components is essential to the way NMP distinguishes organized mechanisms from aggregates. Aggregate properties are simply a sum of the properties of their parts, which change through the addition and subtraction of parts; the parts of aggregates can be rearranged or intersubstituted and the whole can be decomposed and recomposed without altering the properties or behavior of the whole. "These features of aggregates hold because organization is irrelevant to the property of the whole." ${ }^{50}$ In contrast to aggregates, mechanisms are non-aggregative, they are "not mere static or spatial patterns of relations, but rather patterns of allowance, generation, prevention, production, and stimulation. There are no mechanisms without active organization, and no mechanistic explanation is complete or correct if it does not capture correctly the mechanism's 
active organization." ${ }^{51}$ NMP contends that nature is replete with a spectrum of forms of organization that extends from truly aggregative properties, which are relatively rare, through a whole range of organized parts and causes to very complex organized mechanisms, sometimes characterized as forms of mechanistic emergence by NMP. ${ }^{52}$ "Organization is the interlevel relation between a mechanism as a whole and its components. Lower-level components are made up into higher-level components by organizing them spatially, temporally, and actively into something greater than a mere sum of the parts." 53 Craver argues at length that mechanisms, "by virtue of their organization, are able to do things that their parts cannot do individually. They can respond to inputs that the parts alone cannot detect. They can produce behaviors that their parts alone cannot produce. There are generalizations about causal relevance that are true of mechanisms and false of their parts." ${ }^{4}$

\subsubsection{Levels of Mechanisms}

The commitment to ontic organization of mechanistic components by NMP is connected to its antireductionist account of the hierarchy of integrated levels in the mechanisms of biology and neuroscience. Talk of levels, however, is ambiguous; in order to distinguish levels of mechanisms from other types of levels, Craver provides an extensive field guide to levels, the rich details of which exceed the scope of this article. ${ }^{55}$ In brief, Craver contrasts levels of causality, which are relations between distinct entities, from levels of mechanisms, which are relations between a whole and its parts. The distinctive feature of levels of mechanisms is mechanistic composition, which Craver contrasts with levels of size, formal mereology, aggregativity, and spatial containment. Mechanistic composition takes the behaving components of a mechanism to be salient for the individuation of levels over any distinguishable boundaries between levels of objects or their sizes. Consequently, two or more items belong to the same level of a mechanism if they belong to the same mechanism and neither item is a component of the other. Working components of a mechanism, however, are at a lower mechanistic level than the mechanism taken as a whole. Craver defines levels of mechanisms in terms of the relationship between system $S$ 's $\psi$-ing behavior, taken as a whole, and some $\varphi$-ing activity of a component entity $X$ of the system $S$, where the relata are the behaving mechanism at the higher-level and its component acting-entities at lower-levels. Accordingly, $X$ 's $\varphi$-ing is at a lower-level of mechanistic organization than $S$ 's $\psi$-ing if and only if $X$ is a component entity of $S$ and $X$ 's $\varphi$-ing is a component activity in $S$ 's $\psi$-ing. ${ }^{56}$

\subsubsection{Causal and Constitutive Relations}

Craver's account of levels of mechanisms is connected to his sharp distinction between intralevel causal relations and interlevel constitutive relations. 
Levels of mechanisms are a kind of part-whole constitutive relation that is not causal. There is no "interlevel causation" or "causal interaction" between items at different levels for Craver. If we accept "the common assumptions that causal relationships are contingent and that cause and effect must be wholly distinct" then there can be no conflation of the levels of mechanisms with causal relationships. ${ }^{57}$ The component parts of the mechanism are not causes that are contingently related to distinct effects identified with the behavior of the mechanism as a whole; rather, the higher-level behavior of the whole mechanism is itself constituted or composed from the organization of its lower-level components, which are themselves constituted from the organization of their own lower-level components. NMP's denial of "interlevel causation" between the behavior of a mechanism as a whole and its organized component parts does not entail the rejection of interlevel dependency; this is captured by constitutive relationships.

The behavior of the whole is dependent on the behavior of the components in such a way that interventions to change the components can change the behavior of the whole and vice versa. While there are not interlevel causal relations in [levels of mechanisms], there are many interlevel relations of dependency, and thereby interlevel relations of regularity and predictability. One can disrupt spatial memory by ablating the hippocampus or knocking out NMDA receptors. ${ }^{58}$

In short, causal relations concern the intralevel causes of entities and their activities at the same level, constitutive relations pertain to the interlevel forms of dependency among the behaviors of whole mechanisms and their organized component parts at different levels.

\subsection{6 "Top-Down Causation Without Top-Down Causes"}

This brings us to the revisionary account of top-down causation and emergentism of Craver and Bechtel. They accept that the language of top-down and bottom-up interlevel "causation" employed by scientists often does identify "perfectly coherent and familiar relationships" between the activities of wholes and the activities of their component parts. However, for Craver and Bechtel, it is a category mistake to conceptualize the interlevel whole-part dependency between levels of mechanisms as a form of topdown or bottom-up causes, given standard assumptions about (efficient) causation. They argue that any unobjectionable cases of "interlevel causation" referenced in the scientific literature can be reinterpreted, without remainder, as "appeals to mechanistically mediated effects."

Mechanistically mediated effects are hybrids of constitutive and causal relations in a mechanism, where the constitutive relations are interlevel, 
and the causal relations are exclusively intralevel. Appeal to top-down [or bottom-up] causation seems spooky or incoherent when it cannot be explicated in terms of mechanistically mediated effects. ${ }^{59}$

The account of mechanistically mediated effects of Craver and Bechtel not only provides an alternative interpretation of reputed cases of interlevel bottom-up or top-down causation, but also establishes concrete grounds for distinguishing mechanistic emergence from spooky emergence, via the presence or absence, respectively, of mechanistic hybrids of constitutive interlevel and causal intralevel relations. "Mechanistic (or organizational) emergence thus understood is ubiquitous and banal but extremely important for understanding how scientists explain things." ${ }^{60}$ According to NMP, mechanistic or organizational emergence is common to the entire biological world, for organizational emergence pervades the hierarchy of multilevel constitutive and causal relationships described and explained by the mechanisms discovered by scientists. Unlike mechanistic organizational emergence, spooky or strong emergence lacks mechanistic explanations for it fails to provide the explanatory hybrid of constitutive and causal relations that are essential to mechanistic emergence. Consequently, the sense of "level" connected with strong emergence must be distinguished from NMP's account of levels of mechanisms. ${ }^{61}$ "Levels of mechanisms are constitutive levels; levels of strong emergence are not. For this reason, the notion of strong emergence can borrow no legitimacy from its loose association with the levels of mechanisms so ubiquitous in biology and elsewhere." ${ }^{62}$ Craver and Bechtel conclude:

This hybrid framework provides a way to understand most, if not all, the cases for which appeal to top-down causes seems compelling. There may be cases that cannot be handled by this account, but if there are, those who invoke the notion of top-down causation for them owe us an account of just what is involved ... Although our explication of interlevel causation in terms of mechanistically mediated effects renders reference to top-down causation unproblematic, it does not show that the phenomenon is unimportant. The biological world, and much of the world besides, is populated by multilevel mechanisms. Talk of interlevel causation is merely a misleading way to talk about an explanatory interlevel relationship that, upon close inspection, does not involve interlevel causes. ${ }^{63}$

In sum, the NMP in biology, neuroscience, and psychology defends an account of mechanistic ontic explanations. This account consists in explanations of how a multilevel hierarchy of organized intralevel causal interactions among components entities can constitute the interlevel organizational emergence of mechanisms and their manifestation of various phenomena. 


\section{Points of Agreement Between Hylomorphism and New Mechanisms}

Those familiar with the basic principles of hylomorphism will recognize in the foregoing summation of the new mechanist philosophy many points of agreement-and even some identical doctrines expressed in a different nomenclature-with Neo-Aristotelian hylomorphism. I shall take note of some of the more fundamental points of agreement, beginning with hylomorphism's organization realism. As was noted before, exponents of hylomorphism are minimally committed to some account of organization or structure realism. Hylomorphism's organization realism touches upon a variety of interconnected philosophical topics, such as Aristotle's substance-attribute ontology, property, causal and explanatory pluralism, theory of composition and parthood, and Aristotle's metaphysics of act and potency-which overlaps with significant features of contemporary views in the metaphysics of causal powers. Let us begin with NMP's and hylomorphism's shared commitment to the reality of organization.

\subsection{Organization Realism}

Hylomorphists understand the organization of material things to be a real and fundamental ontological and explanatory principle that accounts both for the very nature of what a distinct physical substance is and what its powers enable it to do.

Hylomorphism claims that structure (or organization, form, arrangement, order, or configuration) is a basic ontological and explanatory principle. Some individuals, paradigmatically living things, consist of materials that are structured or organized in various ways. You and I are not mere quantities of physical materials; we are quantities of physical materials with a certain organization or structure. That structure is responsible for us being and persisting as humans (as opposed to, say, dogs or rocks), and it is responsible for us having the particular developmental, metabolic, reproductive, perceptive, and cognitive capacities we have. ${ }^{64}$

The organization realism of hylomorphism corresponds to NMP's account of the ontic structure of spatial, temporal, and active organization in biological organisms as a significant factor-along with the organized component entities and activities - that constitute any mechanism. One way NMP distinguishes itself from classical mechanisms is by emphasizing that organization is an ineliminable and irreducible feature of mechanistic explanations. For NMP, spatial, temporal, active organization is a fundamental explanatory factor that accounts for the way the causal component parts constitute a mechanism as a whole. While the interaction of component entities and 
their activities explain the intralevel causal relations in mechanisms, it is the active organization of these components that provides the most salient explanatory factor of the interlevel constitutive relation between the parts of a mechanism and the mechanism as a whole. It is this constitutive relation that enables and so explains, in part, what the mechanism as a whole is, what it is able to do, and accounts for the persistent unity and organization of the component parts of some mechanistic functional whole. In short, for $N M P$, as with hylomorphism, organization matters, makes a difference, and it counts.

\subsection{Property, Causal, and Explanatory Pluralism}

Hylomorphism's commitment to property, causal, and explanatory pluralism resonates with numerous features of NMP. For hylomorphism, every organized physical entity and its activities possess two kinds of properties:

Organizational or Formal Properties: Properties due to organization or being integrated within an organized entity

Material Properties: Properties due to matter irrespective of its being integrated within an organized entity ${ }^{65}$

Because hylomorphism maintains that all physical entities are constituted by the organization of their material components, a complete description and explanation of any physical, chemical, biological, neurophysiological, psychological, ethological, or anthropological phenomenon must detail both the formal properties due to organization and the material properties due to the materials that are organized. Jaworski provides a number of illustrations of these two kinds of properties. Subatomic particles, atoms, and molecules have material properties like mass regardless of whether they are taken up into the life of an organism and integrated into its formal organization. But whenever such entities do become organized constitutive parts of a living organism, they contribute formal properties to the animated activities of these living things; for instance, nucleic acids, hormones, and neural transmitters have such formal properties as being genes, growth factors, and metabolic and behavioral regulators. The atomic or fundamental material properties of a strand of DNA might not be modified by its surrounding environment, but it exhibits new formal properties when it is integrated into the organization of a cell and is enlisted in the cell's activities. ${ }^{66}$

Hylomorphism is also committed to causal and explanatory pluralism. There are many different kinds of causes and causal relations; causes are explanatory factors and explanatory relations target causal relations. In the case of rational animals, like human persons, Aristotelian hylomorphists distinguish between personal and sub-personal level descriptions and explanations. ${ }^{67}$ Personal level explanations address rational patterns of organized human activities that are best explained by reasons for action, but personal 
level explanations also appeal to perceptions, desires, emotions, and other forms of psychosomatic cognitive and motivational factors that humans share with other animals. Subpersonal level descriptions and explanations provide the material causes of these personal level descriptions and explanations, and this includes the kinds of mechanisms treated by NMP.

While most proponents of NMP do not speak in such terms, their commitment to multilevel ontic explanations of mechanisms constituted by the organization of a plurality of component entities with different intralevel causal activities, can be explicated in terms that are consistent with hylomorphism's commitment to property, causal, and explanatory pluralism. For as we have seen, the entities at distinct levels of mechanisms have different properties that enable them to engage in different causal interactions with other intralevel entities. The properties and causal activities of the components of a mechanism are typically very different from the behavior and causal capacities of the mechanism as whole, which is constituted from the organization of such components. The coordinated opening and closing of transmembrane ion channels (along with the interaction of many other component entities) that constitute the underlying mechanism of a neuron's action potential, are very different from the phenomenon of an action potential itself, such as the rapid and transient changes in the electrical potential difference across a neuron's membrane and the unidirectional propagation of the action potential from the cell body to the axon terminal.

For NMP, mechanistic explanations enlist a hybrid of constitutive and causal relations that are consonant with hylomorphism's distinction between material and formal properties. While there are important differences among the organized components that underline the mechanism for an action potential as well as variations among action potentials, nonetheless, the action potentials of neurons do possess a range of similar material properties, causes, and explanations that constitute organized components for a myriad of higher-level neural assembles and neural systems (e.g., peripheral, central, motor, sensory, and a host of more fine-grained systems for recognition, memory, language, attention, etc.). And these latter wholes or systems have components with distinct formal properties, causes, and explanations in virtue of the way neurons and patterns of action potentials are organized constituents of these higher-level systems.

Explanations for NMP and hylomorphism aim to account for the way reality is, to capture its ontic structure. For NMP, "Mechanistic decomposition cuts mechanisms at their joints." ${ }_{68}$ This does not mean higher-level phenomena are explanatorily reduced to the mechanisms of a lower-level; rather, such joint-carving requires integrative explanations of the hybrid of constitutive and causal relations that comprise mechanisms. In short, hylomorphism and NMP agree that descriptions and explanations must take into account the plurality of causal and organizational factors that constitute living organisms. 


\subsection{Composition, Wholes, and Parts}

As with NMP, there are a range of disagreements among hylomorphists about the best accounts of causality, the metaphysics of powers, and theories of composition and parthood. Because such internal disagreements do not distinguish hylomorphism from other views, they do not provide grounds for showing the incompatibility of hylomorphism and NMP. One area of agreement pertains to some general claims about composition and parthood that follows from the organizational realism and plurality of properties, causes, and explanations maintained by NMP and hylomorphism. Hylomorphism is committed to a number of positions pertaining to the nature of composition and mereology, that is, a theory about parts and wholes. ${ }^{69}$ Let us take note of widespread agreement between hylomorphism and NMP on such issues. First, for hylomorphism, organized entities and activities are more than the sum of their parts; an entity includes both its material parts and the organization of these parts. New mechanists also maintain "Every complex is a mereological sum, but mechanisms are always literally more than the sum of their parts. Any account of the composition relation in [levels of mechanisms] must accommodate this fact." ${ }^{70}$

Second, hylomorphism holds that the organization of an entity and its activities can persist and remain the same notwithstanding the continuous ebb and flow of its material parts through its interactions with the environment. The persistence conditions of the entity are contingent on the continuity of its organization of some material parts, not on the continuity of these material parts. As Jaworski points out, when an animal breathes, the oxygen atoms it inhales become organized in a particular way by becoming integrated into the organized material parts of the animal and its metabolic activities. Conversely, when the animal exhales, carbon atoms cease to be organized material parts of the overall organization of the animal and its metabolic activities. ${ }^{71}$

Third, the nature of parthood requires being integrated into the organization of the whole and contributing to the overall functioning of the whole and its activities, and parts are distinguished according to the different ways in which they contribute to the different activities of the whole. "Genes and messenger molecules are both parts of cells; they both contribute to the cell's activities, and what distinguish them from each other are the different roles they play in protein synthesis: their different jobs within the cell qualify them as different parts of it." 72 Many hylomorphists accept the existence of a range of proper parts, especially biofunctional parts in living things (from organelles and cells to distinguishable organs and their organic parts), and recognize the organic parts identified by our best empirical descriptions and explanations.

Fourth, even though hylomorphists are divided over the details of the best theory of parthood, most hylomorphists would grant the following general account of parthood from Jaworski: "roughly, $x$ is a part of $y$ if $x$ 


\section{Daniel D. De Haan}

contributes to the activities of $y$. An electron is a part of me, for instance, if it contributes to my activities-if, say, it depolarizes one of my cellular membranes. This notion of composition dovetails with work in biology, philosophy of biology, and philosophy of neuroscience."73 Robert Koons's version of staunch hylomorphism defends an account of Parts as Sustaining Instruments (PASI). According to PASI, "the persistence of the whole is grounded in the ongoing cooperation of the parts, and the active and passive powers of the parts are grounded in corresponding primary powers of the whole. In addition, the whole acts through the parts, as teleologically subordinate instruments." Furthermore, PASI "ties the whole and parts together in such a way that the whole is neither existentially separate from its parts nor able to act in a way that is separate from the actions of its parts. The staunch hylomorphist must accomplish two things: (1) ensure that the persistence through time of the composite whole is grounded in the cooperation of its parts, and (2) ensure that the whole cannot act or be acted upon except, at least in part, doing so 'through' the powers of its parts." Accordingly, Koons offers the following "Definition of 'proper part': $x$ is a proper part of $y$ at $t$ iff $x$ is a sustaining instrument of $y$ at $t . " 74$

Fifth, hylomorphism is committed to an account of fundamental entities constituted by a complex hierarchy of parts and causal powers comprised of organized systems and sub-systems with corresponding activities and subactivities. This is paradigmatically the case with living organisms. ${ }^{75}$

As we have seen, NMP is committed to a similar dynamic account of the unity of the organization that constitutes the distinct levels of mechanism, and an account of parthood and levels of mechanisms whereby the organized activities of component entities contribute to the activities of the whole. Indeed, the general hylomorphic account of parthood is nearly identical to the aforementioned account of the individuation of component parts within the levels of a mechanism from Craver. ${ }^{76}$

\subsection{Levels of Organization and Emergence}

The causal powers of a higher-levels of organization emerge or are educed from the potentialities of the materials they organize and integrate. Because higher-level systems of, say, living organisms are composed from the organized materials of lower-level systems, the activities of an organism's higherlevel powers cannot violate the fundamental activities that belong to the lower-level organic systems and chemical and physical subsystems. Indeed, the novel activities of higher-level powers depend upon the activities of lower-level activities that compose them. "It is because fundamental physical entities behave in stable, characteristic ways that they can be recruited to play in organisms the higher-level roles they do. It is because electrons have a characteristic mass and charge, for instance, that they are able to operate as membrane depolarizers within certain structures." 77 Hylomorphism's understanding of the eduction or emergence of higher-level properties is 
therefore radically different from more well-known accounts of strong emergence.

First, hylomorphism rejects standard accounts of strong emergentism that maintain higher-level emergent properties are products generated or caused by the organization of lower-level properties. For hylomorphism, educed or emergent properties are not distinct from the organization of lower-level organization; rather, the hylomorphic emergent properties are constituted from the organization of their components. Second, it is the central form of a physical substance that grounds all of its conjugate properties, whether they be higher-level psychosomatic powers or the lower-level biochemical powers that are components within psychosomatic powers. Finally, hylomorphic emergence is not unique to psychological powers or phenomenal consciousness, but is ubiquitous to the entire biological world.

The hylomorphic account of hierarchies of organized levels that constitute an organism-where a higher-level phenomenon is educed or emerges from the organization of lower-level components-is nearly identical to Craver's presentation of mechanistic emergence of higher-levels of mechanisms from the organization of lower-level mechanistic components.

When one says that atoms compose molecules, which are organized into cells, which are linked into networks from which mental properties spookily emerge, the first three steps are upward steps in a hierarchy of levels of mechanisms, but the last is not. The ability of organization to elicit novel causal powers (that is, nonaggregative behaviors and properties) is unmysterious both in scientific common sense and common sense proper ... Appeal to strong or spooky emergence, on the other hand, justifiably arouses suspicion. ${ }^{78}$

Both NMP and hylomorphism reject standard accounts of emergence in favor of complementary, if not equivalent, alternative conceptions of organizational emergence.

In sum, hylomorphism is committed to a range of issues concerning (1) organization realism, (2) property, causal, and explanatory pluralism, (3) the composition of wholes and parts, and (4) levels of organization that are compatible, if not in complete agreement, with stands that NMP takes on these same topics. In short, these fundamental features of hylomorphism set in relief a significant range of points of agreement, and the possibility for fruitful collaboration, between proponents of hylomorphism and NMP.

\section{Points of Disagreement Between Hylomorphism and New Mechanisms}

The synoptic character of this comparative essay prevents me from digging any deeper into the details and more substantive arguments for and against the connections I have been making between hylomorphism and NMP. My 


\section{Daniel D. De Haan}

presentation of hylomorphism will certainly leave the metaphysician unsatisfied, and my digest of NMP will have the philosophers of science yearning for a more critical examination of empirical literature. I realize more needs to be said to sift out the exact points of substantive agreement from other mere naïve correlations between superficially similar positions. I conclude by taking up some apparent objections and potential points of disagreement between hylomorphism and NMP.

\subsection{Substance-Attribute Ontology: Central and Conjugate Forms}

The first concerns the substance-attribute ontology of hylomorphism, especially its distinction between the central and conjugate formal organization of a substance. Are these features of staunch hylomorphism compatible with NMP?

It is important to point out a difference of scope between the principal concerns of hylomorphism and NMP. NMP is a philosophy of science; hylomorphism is an ontology. Hylomorphism aims to provide a general ontology of the physical world. NMP is not specifically concerned with addressing more general metaphysical questions about the nature of organisms, substances, fundamentality, and so forth; rather, it is focused on the concrete macro and micro ontic structures of organisms that constitute the mechanisms discovered in biology, neuroscience, and psychology. Few of these forms of ontic organization will prove to be ontologically fundamental; most will comprise forms of conjugate attributes. Consequently, the distinction between substantial organization and conjugate organization does not arise for the more specialized studies of NMP. Nevertheless, given the basic contentions of NMP, there seems to be no principled reason that militates against an exponent of NMP defending a substance-attribute ontology that squares with the multileveled view of the new mechanists (as Glennan, Maley, and Piccinini do), ${ }^{79}$ or even from adopting hylomorphism's full-fledged distinction between the substantial organization of substances and the conjugate organization of its components. Likewise, there is nothing to prevent hylomorphists from looking to NMP (as Jaworski does) to provide a more concrete empirical account of the organization of biofunctional components of the mechanisms or capacities that comprise the conjugate attributes of a substance's proper parts.

The general strategy of NMP's defense of hybrid causal and constitutive explanations is to acknowledge mechanistic emergence wherever there are higher-level wholes constituted from the organization of causal components. Insofar as the staunch hylomorphist employs a similar strategy to make the case that substances constitute distinct organized wholes over and above their organized components, then the staunch hylomorphism stands on solid ground-by NMP's own lights-for distinguishing between substantial and conjugate forms of organization. Seen in this light, a new mechanist-cum-staunch hylomorphism could hold that the 
substantial form and matter of a substance, say, of an animal, explains a thing's fundamental nature and grounds the overall multilevel organization of its matter and a wide range of physical, chemical, biological, and psychological powers. A substance's higher-level psychological powers, say, memory, are form-matter conjugate properties that admit of mechanistic explanation via NMP's hybrid constitutive and causal relations. The causal relation of mechanistic explanations concerns the way the causal powers of these organized material component entities enable them to engage in intralevel interactions. The constitution relation of mechanistic explanation pertains to the way the organization of these material component parts compose form-matter conjugate properties. The conjugate form of a psychological power explains the active, spatial, and temporal formal organization of the zones of organized material components of some power, say, neural distributed within the medial temporal lobe (and perhaps elsewhere), which in turn are mechanistically explained by the formal organization of these component's organized material subcomponents, say, the patterned firing rate of individual pyramidal neurons in the hippocampus and the diffusion of glutamate into the synaptic cleft. Similarly, these zones of organized material components have various material and formal properties that explain the range of causal interactions these component parts are capable of engaging in, as well as the way their enabling, precipitating, inhibiting, and modulating conditions influence how these mechanistic components constitute (or fail to constitute) the manifestation of a higher-level mechanism or capacity, like the animal actually remembering. ${ }^{80}$ In short, far from being incompatible, hylomorphism and NMP provide a wealth of insights for thinking about diverse forms of organization found among substances and their attributes.

\subsection{Emergentism and Bottom-Up and Top-Down Causation}

These points bring us to another apparent incompatibility between NMP and hylomorphism. Most defenders of NMP adopt Craver's and Bechtel's rejection of top-down and bottom-up interlevel causation in favor of their distinction between intralevel causation and interlevel constitutive relations. However, many hylomorphists defend accounts of top-down or downward causation. This conflict, I suggest, is less substantive and more terminological. The causal pluralism of hylomorphism opens it up to more forms of dependence than those captured by standard contemporary views on efficient causation. Classically, Aristotelians distinguish four kinds of dependence, and so four distinct kinds of causes and explanations: material, formal, efficient or agential, and final causes. The material stuff or components of some entity make a difference to what that entity is and can do; material causes explain this kind of dependency. As we have seen, the organization of these material components also matters, makes a difference, and counts; formal causes explain the dependency of a whole 


\section{Daniel D. De Haan}

on the organization of its material components. Efficient causes explain the range of dependencies between events, properties, and substances that consist of moving, exerting force, attracting, repelling, producing, generating, corrupting, transforming, and so on. Final causes explain the range of functional dependencies, the way the formally organized material components are ordered towards constituting and enabling powers of efficient causation to perform or produce stereotyped, organized operations, products, properties, substances, and so forth in organized material objects with reciprocal powers.

NMP rightly distinguishes its constitutive relation between the component parts and the mechanism as a whole from standard accounts of (efficient) causation, which maintain that causes and effects are distinct. However, Aristotelian hylomorphism defends two forms of causal dependency that are equivalent to NMP's constitution relation, namely, its understanding of the way a whole is constituted or composed from the union of its formal and material causes, that is, the way the organization of material components cause the whole. This constituted whole is not a separate effect or entity produced and distinct from the formal and material causes, the whole as effect is united with and dependent on its intrinsic formal and material causes. In short, the disagreement here is terminological. The causal pluralism of NMP and hylomorphism permits both views to stipulate accounts of "causality" that either pragmatically appease widespread assumptions about causality among their interlocutors and introduce alternative terms to capture other forms of dependency (such as constitution or grounding or realization) or that maintain some version of Aristotelian causal pluralism, albeit recognizing that this approach hazards being misunderstood by contemporary philosophers.

A similar conclusion can be drawn with respect to downward causation. Neither NMP nor hylomorphism need to be committed to a strong emergentist view of downward causation, where the manifestation of higherlevel causal powers efficiently cause lower-level effects. So, for some strong emergentists, psychological powers not only manifest psychological efficient causes like an intention to walk home, but also efficiently cause the motor cortex in the brain to generate the appropriate bodily movements of an intentional action. Instead, NMP and hylomorphism can maintain that intentional actions are comprised of a plurality of causes or a hybrid of constitutive and causal relations, where higher-level factors like practical reasoning and other psychological motivations can provide personal level explanations for an intentional action. Again, given causal and explanatory pluralism, personal level explanations do not compete with, but make a distinctive complementary difference to mechanistic explanations of an embodied intentional action. An embodied intentional action is itself a whole composed of a complex hierarchy of levels of mechanisms, all of which are integrated and engaged by the higher-level psychological powers for intentional action. On this score, intentional actions (like walking 
home) should not be conceived as mere efficient causes acting on sites of the nervous system. Rather, since higher-level psychological phenomena (like intentional actions) are enabled by and constituted from the organization of lower-level mechanisms (such as the nervous system), intentional actions consist of rationally coordinated patterns of activation of the organized causal components that underlie and constitute them. In this way, mechanistic explanation

offers significantly more insight into what interlevel integration is, into the evidential constraints by which interlevel bridges are evaluated, and into the forces driving the co-evolution of work at different levels. Constraints on the parts, their causal interactions, and their spatial, temporal, and hierarchical organization all help to flesh out an interlevel integration. Finally, mechanists repeatedly recognize the need to not only look down to the constitutive mechanisms responsible for a given phenomenon (emphasized by classical reduction models), but also to look up and around to the context within which the phenomenon is embedded: interlevel integration is an effort to see how phenomena at many different levels are related to one another . . ${ }^{81}$

A great deal more needs to be said about the way hybrid explanations from staunch hylomorphism and NMP would address issues of psychological operations and causal powers. I hope this sketch is at least suggestive of the possibility of fruitful exchange of perspectives from these two complementary approaches to multilevel organization realism and causality. NMP provides a rich way to think more concretely and empirically about the kinds of embodied causal powers of organized components which hylomorphism addresses in its more abstract ontological framework.

\subsection{Teleology and Mechanisms}

I conclude with what might seem to be the most controversial point of disagreement between staunch hylomorphism and the new mechanist philosophy, namely, the compatibility of mechanistic explanations with teleology and final causality. Aristotelian hylomorphism seems to be wed to some form of teleological explanation; after all, final causality is taken to be the cause of causes for Aristotelians. The difficulty is that a widely accepted script tells us that mechanistic science caused the final end to teleological explanations. ${ }^{82}$ Consequently, if mechanist explanations are against teleological explanations and Aristotelian hylomorphism requires teleology, then the two positions seem to be fundamentally at odds. As with many disputes, the real point of disagreement is more complicated.

First, while it is the case that Aristotelian hylomorphists are committed to some robust realist doctrine of teleology, there are some hylomorphists that are neutral about the nature of teleological explanation. Surprisingly, 


\section{Daniel D. De Haan}

a similar range of views about teleology has emerged among new mechanists, but the battle line that divides the different views among NMPs is not drawn where one might expect. The contention at issue is not about teleology versus no teleology; rather, the recent dispute among NMPs is between ineliminable perspectivalism about the function of teleological explanations in mechanistic explanations and realism about hybrid teleological-cummechanistic ontic explanations. Craver defends a version of perspectivalism on teleological functions. He holds that our explanatory interests render teleology ineliminable from our efforts to make the world intelligible. Craver distinguishes his mechanist design stance from the "associations with adaptationism and optimality" characteristic of Daniel Dennett's well known account of the intentional, design, and physical stances. Craver's conclusion is worth quoting at length, as it provides one among many stark examples of how misleading the received wisdom is on the incompatibility of mechanisms and teleology.

In the contemporary mechanical philosophy, functional and mechanistic descriptions work in tandem to bring intelligible order to complex systems. By identifying functions within such systems, one approaches the system with some set of interests and perspectives in mind. One might be interested in understanding how parts of organisms work, how they break or become diseased, or how they might be commandeered for our own purposes. Regardless of which perspective one takes, the identification of functions is a crucial step in the discovery of mechanisms. We no longer speak of mechanisms simpliciter, but rather as mechanisms for some behavior. Mechanistic descriptions thus come loaded with teleological content concerning the role, goal, purpose, or preferred behavior of the mechanism. This teleological loading cannot be reduced to features of the causal structure of the word, but it is ineliminable from our physiological, and particularly neural, sciences, precisely because their central goal is to make the busy and buzzing confusion of complex systems intelligible and, in some cases, usable. ${ }^{83}$

Craver concludes that adopting his mechanist design stance makes intelligible the way a mechanism as a whole exhibits some behavior which is constituted from the organization and interaction of the components of the mechanism. It remains an open question for Craver whether or not these teleological aspects of the new mechanist worldview are reducible, without any remainder, to other features of the causal structure of the world; "here we have a, perhaps the, central puzzle that any properly mechanical understanding of mind must someday face." 84

For many, Craver's rather rich perspectivalism about teleology will be real enough. ${ }^{85}$ Functions are ineliminable features within mechanistic explanations, even if they are not real. Craver's account is honest about the exigency 
of employing teleological explanations in mechanistic explanations. More recently, Corey Maley and Gualtiero Piccinini have argued that Craver's perspectivalism is inadequate and that new mechanists should embrace a realist account of teleological explanations in psychology and neuroscience. ${ }^{86}$ Perspectivalism understands all ascribed teleological functions to be "observer-dependent and hence subjective, and in no way objective." ${ }^{87}$ For perspectivalism, the range of explanatory interests accounts for the proliferation of otherwise unchecked teleological attributions. If we adopt the perspective of an organism's survival, then the function of the heart is to pump blood, but seen from the perspective of diagnosing heart conditions, the heart's function is to make thumping noises, and so forth. ${ }^{88} \mathrm{NMP}$ proponents like Maley and Piccinini are not impressed with perspectivalism's line of argumentation against realism about functions. They argue, contrary to perspectivalism, that the function of the heart is to pump blood, and assigning the heart this function is independent from any observer's perspective or explanatory interests. Of course, some traits have multiple functions, but again, this is not due to multiple perspectives. According to Maley and Piccinini:

Perspectivalism does not do justice to the perspectives we actually take in the biological sciences. If we could identify non-teleological truthmakers for teleological claims, we would avoid perspectivalism and deem functions real without deeming them mysterious. That is our project. $^{89}$

Indeed, if one is willing to accept Craver's argumentative strategy in favor of taking mechanisms and organization to provide ontic explanations, it becomes difficult to resist the similar argumentative strategy in favor of taking teleology to provide ontic explanations as well. I leave the debate here.

My aim, once again, is to show that proponents of the NMP-of both perspectivalist and realist stripes-take teleology seriously. Within this debate between realists and perspectivalists the function of teleological descriptions and explanations remains controversial for new mechanists and hylomorphists. In short, these more restricted disagreements about teleology do not divide NMP and hylomorphism. NMP perspectivalism about function is compatible with a variety of non-Aristotelian versions of hylomorphism that are neutral or even skeptical about the reality of teleology. Similarly, a NMP defender of teleological realism, like Maley and Piccinini, can adopt an Aristotelian hylomorphism that endorses finality realism. This conclusion is significant, for this compatibility between hylomorphism and the new mechanists reveals that the long-standing script that teleology and mechanisms are fundamentally opposed, is mistaken. For the NMP's recognition of organizational realism and the significance of teleology in biology, neuroscience, and psychology provide an amiable philosophy of science ally to Aristotelian hylomorphism. 


\section{Daniel D. De Haan}

\section{Conclusion}

Neo-Aristotelians and hylomorphists often participate in debates in philosophy of mind and metaphysics, but they rarely address topics in philosophy of biology, neuroscience, and psychology. My aim has been to introduce Aristotelian hylomorphists to the new mechanist philosophy in biology, neuroscience, and psychology, and, I hope, to convince hylomorphists that there is a real potential here for fruitful constructive engagement with scientific research, philosophy of science, and especially with the new mechanist philosophy. In this essay, I have argued that Neo-Aristotelian hylomorphism is perfectly compatible with the account of mechanisms presented by NMP. I have established that there are substantial points of agreement between the two views on fundamental issues that typically distinguish hylomorphism and NMP from other views. In light of such common points of agreement, I believe their integration would be mutually beneficial. Hylomorphism provides a robust abstract ontological framework for NMP, and NMP can enrich hylomorphism with its detailed concrete exposition of the complex hierarchy of organized mechanisms discovered by biologists, neuroscientists, and psychologists. Finally, I have shown that despite any historical controversies concerning the compatibility of teleology and mechanisms, there are no principled reasons for taking Neo-Aristotelian teleology and the mechanisms of the new mechanistic philosophy to be incompatible. ${ }^{90}$

\section{Notes}

1 Pasnau (2011, 2004), Cartwright (1999), Gilson (1995), Lonergan (1992).

2 Jaworski (2016: 3, 159). I have modified Jaworski’s slogans for terminological consistency.

3 In order to elucidate the fundamental claims of hylomorphism, I draw on William Jaworski's recent presentation of hylomorphism because it is systematic, rigorous, and it engages a wide range of familiar issues in contemporary metaphysics, philosophy of mind, and philosophy of science (including proponents of $N M P)$. I focus on the features of Jaworski's account that are shared, with some qualifications, by most contemporary hylomorphists and I avoid getting into more controversial topics and internal turf wars within hylomorphic circles. See also Brower (2014), Koons (2014), Lonergan (1992), Marmodoro (2013), Oderberg (2007), Ross (2008).

4 Koons (Forthcoming), Oderberg (2014: 177).

5 Hylomorphists disagree among themselves about the way formal organization transforms the material components of a whole. I say more about this disagreement in note 73 .

6 Jaworski (2016), Lonergan (1992: 456-511).

7 Jaworski's terminology of "structure" aims to provide contemporary nomenclature for discussing hylomorphism; however, due to the many contemporary accounts of "structure," Jaworski spends as much time explaining his own technical philosophical vocabulary as Aristotelian hylomorphists do. I shall deploy a version of Lonergan's more modest revisions to the traditional Aristotelian terminology. Lonergan speaks of central matter, form, act of existence and conjugate potencies, forms, and operations, over substantial form, prime matter, act 
and accidental form, secondary matter, and operations. Lonergan's transposed terminology liberates hylomorphism from unnecessary equivocations and infelicities. An illustration of each will be instructive. First, there is the equivocal and overlapping use of the term "accident" from the ten categories and the five predicables. For example, the color green and the intellect are both accidents in the category of quality, but from the perspective of the predicables the intellect is a property and green is an accident of a human. Second, there are many bizarre consequences that result from an excessive conservativism with respect to Aristotelian taxonomies. For example, in the case of a human, like Socrates, his separable attributes like having a particular hand (or even these skin cells) is a substantial part, and by resolution falls into the category of substance, but the intellect is an accident; it is a power belonging to the third species of the category of quality. A human can lose its substantial parts, like hands and skin cells, but it cannot lose its intellect, a kind of accident that is a necessary and inseparable concomitant of the specific difference of the human substance as a rational animal. I think such consequences are manifestly problematic and give us good reasons, among the many other philosophical and empirical reasons given by Lonergan, to prefer Lonergan's schemata where hands, skin cells, and the intellect are all distinct kinds of conjugate attributes and only the rational soul is a central form. Finally, Lonergan provides a rich account of the way his hylomorphic schemata explains how an individual thing or substance, constituted by central matter, form, and act, also consists of a complex and integrated hierarchy of explanatory conjugates from physics, chemistry, biology, psychology, and noetics and thereby anticipates the many insights about levels of organization detailed in Jaworski's hylomorphism and the new mechanist approach to genetics, molecular biology, cell biology, neuroscience, and psychology. See Lonergan (1992: ch. 15). "Elements of Metaphysics."

8 Jaworski (2016), Koons (2014), Lonergan (1992), Marmodoro (2013), Marmodoro and Page (2016), Oderberg (2007).

9 Jaworski (2016: 159-62). I have modified Jaworski's slogans for terminological consistency.

10 Jaworski (2016: 177), Lonergan (1992), Ross (2008).

11 "Many contemporary would-be defenders of hylomorphism fail to distinguish their position from contemporary materialism. I will label the resulting theories "faint-hearted hylomorphism." "A staunch hylomorphism involves a commitment to a sparse theory of universals and a sparse theory of composite material objects, as well as to an ontology of fundamental causal powers. Faint-hearted hylomorphism, in contrast, lacks one or more of these elements. On the staunch version of HM, a substantial form is not merely some structural property of a set of elements-it is rather a power conferred on those elements by that structure, a power that is the cause of the generation (by fusion) and persistence of a composite whole through time" Koons (2014: 151).

12 According to David Oderberg, hylomorphism, or his preferred hylemorphism, requires a commitment to much more. "The doctrine of substantial forms is but one part of a system of logically related concepts, principles, and distinctions; to lose one is to lose them all. Form and matter; species and genus; dichotomous classification; act and potency; properties and accidents; even the dreaded doctrine of prime matter-these are all part and parcel of the hylemorphic system, and together they provide a coherent and eminently plausible framework for understanding the essences of things" Oderberg (2007: xi). "Since things are constituted by their essences, those essences themselves must in some way be mixtures of actuality and potentiality. Hylemorphism says that they are-their actuality is form and their potentiality is matter" Oderberg (2007: 65).

13 Koons (2014: 152-3). 


\section{Daniel D. De Haan}

14 Jaworski (2016: 336).

15 Craver and Tabery (2016: $\mathbb{S} 1)$. It is also worth pointing out the influence Aristotelian philosophers of science, like Nancy Cartwright, have had on NMP. More recently, Cartwright and Pemberton have pointed out similarities with their work on powers and activities with NMP. "Our account of change-processes develops previous ideas of Pemberton (2011) that mesh Cartwright's account of nomological machines, involving powers and their contributions, with features taken from the closely related account of mechanisms by Machamer et al. (2000), most notably their account of activities. Activities are important for understanding what the nomological machine does in changing arrangements from one stage to another" Cartwright and Pemberton (2013: 96, n. 8).

16 Craver (2007: 8).

17 Cummins (2000: 140).

18 Machamer et al. (2000: 1). For brief histories and bibliographies concerning the development of NMP, see Bechtel (2007, 2009: 548-53), Craver (2007), Craver and Darden (2013: 26-9), Glennan (2016: $\mathbb{2}$ ).

19 Andersen (2014: 276). See Darden (2016), Glennan (2010).

20 Craver (2007: 271).

21 Craver (2014), Craver (2007), Salmon (1984).

22 Craver (2014: 35).

23 “. . . the ontic mode of thinking about explanation, does not depend on the existence of intentional agents ... A given ontic structure might cause, produce, or otherwise be responsible for a phenomenon even if no intentional agent ever discovers as much" Craver (2014: 36).

24 Craver (2014: 51).

25 Some proponents of NMP, like William Bechtel, are less sanguine about ontic explanations; see Bechtel (2007), Illari (2013), Wright (2012).

26 Craver (2007), Craver and Darden (2013: 48-50), Craver and Tabery (2016).

27 Craver and Tabery (2016).

28 Craver and Darden (2013: 15), Machamer et al. (2000: 3).

29 Bechtel and Abrahamsen (2005: 423), Bechtel and Richardson (2010).

30 Craver (2007: 6).

31 Glennan (2016: $\mathbb{3}$ ).

32 Craver (2007: 1).

33 Craver (2007: ch. 7), Craver and Darden (2013: 167-72, 193-4).

34 Craver and Darden (2013: 21-2). In connection to what they call topping-off and bottoming-out, "In the practice of scientific explanation, decomposition in a given inquiry bottoms out when the investigation reaches entities and activities that are viewed as unproblematic or for which investigators lack tools for further decomposition. Few decompositions extend more than a small number of levels" Craver and Bechtel (2007: 549, n. 5).

35 Craver and Darden (2013).

36 Craver and Darden (2013), Darden (2006), Tabery et al. (2017).

37 Craver and Darden (2013: 19).

38 Glennan (2016).

39 Machamer et al. (2000: 3).

40 Craver and Darden (2013: 20).

41 Bogen (2005, 2008), Craver (2007: ch. 3), Glennan (2016). Aristotelians will be interested in Bogen's efforts to wed Anscombe on causality and productive activities to NMP.

42 Craver and Tabery (2016: $\mathbb{2} 2.3)$.

43 Craver (2007: 5).

44 Glennan (2016: $\mathbb{S}$ ), Machamer et al. (2000: 4).

45 Craver (2007: 5-6). 
46 Craver (2007: 6).

47 Craver and Darden (2013: 16-20).

48 Craver (2007: 6).

49 Craver and Darden (2013: 20).

50 Craver and Tabery (2016: $\mathbb{S}$ 2.4.1), Wimsatt (1997).

51 Craver (2007: 136). “Action potentials cannot be explained by mere temporal sequences of events utterly irrelevant to the phenomenon, but one can derive a description of the action potential from descriptions of such irrelevant phenomena. Action potentials cannot be explained by mere patterns of correlation that are not indicative of an underlying causal relation. Irrelevant byproducts of a mechanism might be correlated with the behavior of the mechanism, even perfectly correlated such that one could form bridge laws between levels, but would not thereby explain the relationship. Merely finding a neural correlate of consciousness, for example, would not, and is not taken by anyone to, constitute an explanation of consciousness" Craver and Tabery (2016: $\$ 3.1)$.

52 Craver and Tabery (2016: $\mathbb{2}$ 2.4.1).

53 Craver (2007: 189).

54 Craver (2007: 227). My emphasis.

55 See Craver (2007: ch. 5) "A Field Guide to Levels."

56 Craver (2007: ch. 5).

57 Craver (2007: 179).

58 Craver (2007: 183), Glennan (2010).

59 Craver and Bechtel (2007: 547).

60 Craver and Tabery (2016: $\mathbb{\$} 4.2)$.

61 Craver (2007: ch 5).

62 Craver and Bechtel (2007: 551).

63 Craver and Bechtel (2007: 562).

64 Jaworski (2016: 8).

65 Jaworski (2016: ch. 14), Stump (2012: 60).

66 Jaworski (2016: 106).

67 I employ this distinction akin to the way it is used by Hornsby, McDowell, and Hacker's related account of the mereological fallacy. A similar distinction between the animal level and sub-animal level descriptions and explanations can be employed for non-rational animals. See Hacker and Bennett (2003), Hornsby (2000), McDowell (1994).

68 Craver (2007: 188).

69 Jaworski notes: "Fine and Johnston conceive of hylomorphic structures as relations among something's parts. I conceive of them rather as relations between wholes and their parts: a whole configures or structures its parts. This has important implications for how my hylomorphic theory avoids some versions of Williams' worry" Jaworski (2016: 96, n. 2).

70 Craver (2007: 186).

71 Jaworski (2011: 210).

72 Jaworski (2011: 275).

73 Jaworski (2011: 269). Roughly, staunch hylomorphists can be divided up into minimalists and substantivists about the way formal organization transforms the ontological identity of material components. Minimalists, like Jaworski (and perhaps pluriformists like Avicenna and Duns Scotus), hold that the formal identity of the materials remain fundamentally the same whether they exist in the wild or as integrated material parts that depend upon the organization of the whole. Radical minimalists about formal transformation of materials go so far as to say that sometimes these material parts, say fundamental physical particles, are individual substances integrated within more complex substances. Minimalists argue substantivists cannot account for the continuity of the substrate that 


\section{Daniel D. De Haan}

is required for change. Substantivists deny that material components-even the ground-floor physical stuff_can actually remain what they are when they are incorporated into the organization of an inclusive whole: electrons are transformed into animated material components when integrated into the life of an animal. Substantivists contend the minimalist view undermines the integrity, unity, and identity of the organized whole, since parts of a whole cannot possess their own central or substantial formal identity. Radical Substantivists about the formal transformation of materials hold that there cannot be any actual parts in hylomorphic individuals, only potential parts. I leave the debate here.

74 Koons (2014: 171). For a detailed account of various hylomorphic accounts of composition and a defense of PASI, see Jaworski (2016: chs. 6-7, 10, 14), Koons (2014).

75 Jaworski (2016), Lonergan (1992: chs. 6, 8, 15), Ross (2008).

76 Craver (2007: ch. 5).

77 Jaworski (2011: 274-5).

78 Craver (2007: 217).

79 Glennan (2010), Maley and Piccinini (2017).

80 Craver (2007: 122-8).

81 Craver and Tabery (2016: $\mathbb{\$} 5.2)$.

82 Gilson (2009).

83 Craver (2013: 155).

84 Craver (2013: 156).

85 Darden and Craver use William Harvey's (1578-1657) argument for his revolutionary account of the circulation of blood as an illustration of the various constraints (locations, structures/entities, abilities, activities, timing, roles/functions, production, global organization) on mechanism schemata that guide empirical discoveries and the verification of mechanisms. In their section on the importance of roles or functions, they note, "The teleological form of thought embodied in reasoning about an item's role, a form of thought that asks what the different components and activities are for, or what they contribute to a mechanism, is not merely a façon de parler maintained as yet another vestige of Aristotelianism in Harvey's thinking. Rather, it is crucial to understanding how biological mechanisms work: to seeing how a part fits into the organization of the mechanism as a whole" Craver and Darden (2013: 115).

86 In their excellent account of teleological functions as stable causal powers that contribute towards the (objective and subjective) goals of organisms, Maley and Piccinini provide an ontologically serious account of functional or teleological mechanisms that "grounds a system's functions in objective properties of the system or the population to which it belongs, as opposed to features of the epistemic or explanatory context of function attribution." On their account, "functions are an aspect of what a system is, rather than an aspect of what we may or may not say about that system" Maley and Piccinini (2017).

87 Maley and Piccinini (2017).

88 Maley and Piccinini (2017).

89 Maley and Piccinini (2017).

90 I would like to thank the editors of this volume for their helpful comments on previous drafts of this article.

\section{Bibliography}

Andersen, H. (2014) 'A Field Guide to Mechanisms: Part I', Philosophy Compass 9(4): $274-83$. 
Bechtel, W. (2007) Mental Mechanisms: Philosophical Perspectives on Cognitive Neuroscience (New York: Psychology Press).

- (2009) 'Constructing a Philosophy of Science of Cognitive Science', Trends in Cognitive Sciences 1(3): 548-69.

Bechtel, W. and Abrahamsen, A. (2005) 'Explanation: A Mechanist Alternative', Studies in History and Philosophy of Science Part C: Studies in History and Philosophy of Biological and Biomedical Sciences 36(2): 421-41.

Bechtel, W. and Richardson, R. C. (2010) Discovering Complexity: Decomposition and Localization as Strategies in Scientific Research (Cambridge, MA: MIT Press).

Bogen, J. (2005) 'Regularities and Causality; Generalizations and Causal Explanations', Studies in History and Philosophy of Science Part C: Studies in History and Philosophy of Biological and Biomedical Sciences 36(2): 397-420.

- (2008) 'Causally Productive Activities', Studies in History and Philosophy of Science Part A 39(1): 112-23.

Brower, J. (2014) Aquinas's Ontology of the Material World: Change, Hylomorphism, and Material Objects (Oxford: Oxford University Press).

Cartwright, N. (1999) The Dappled World: A Study of the Boundaries of Science (Cambridge: Cambridge University Press).

Cartwright, N. and Pemberton, J. (2013) 'Aristotelian Powers: Without them, What Would Modern Science Do?', in J. Greco and R. Groff (eds.) Powers and Capacities in Philosophy: The New Aristotelianism (London: Routledge): 93-112.

Craver, C. (2007) Explaining the Brain: Mechanisms and the Mosaic Unity of Neuroscience (New York: Oxford University Press).

- (2013) 'Functions and Mechanisms: A Perspectivalist View', in P. Huneman (ed.) Functions: Selection and Mechanisms (Dordrecht: Springer): 133-58.

- (2014) 'The Ontic Account of Scientific Explanation', in M. I. Kaiser, O. R. Scholz, D. Plenge and A. Hüttemann (eds.) Explanation in the Special Sciences: The Case of Biology and History (Berlin: Springer): 27-52.

Craver, C. and Bechtel, W. (2007) 'Top-down Causation Without Top-down Causes', Biology and Philosophy 22(4): 547-63.

Craver, C. and Darden, L. (2013) In Search of Mechanisms: Discoveries Across the Life Sciences (Chicago: University of Chicago Press).

Craver, C. and Tabery, J. (2016) 'Mechanisms in Science', in E. N. Zalta (ed.), The Stanford Encyclopedia of Philosophy (Winter 2016), at http://plato.stanford.edu/ archives/win2016/entries/science-mechanisms/ [last accessed 10.4.17].

Cummins, R. (2000) “"How Does It Work" Versus "What Are the Laws?": Two Conceptions of Psychological Explanation', in F. Keil and R. A. Wilson (eds.) Explanation and Cognition (Cambridge, MA: MIT Press): 117-45.

Darden, L. (2006) Reasoning in Biological Discoveries: Essays on Mechanisms, Interfield Relations, and Anomaly Resolution (Cambridge: Cambridge University Press).

- (2016) 'Reductionism in Biology', in Angus Clarke, (ed.) eLS (Chichester: John Wiley and Sons): 1-7.

Gilson, E. (1995) Methodical Realism: A Handbook for Beginning Realists (San Francisco: Ignatius Press).

- (2009) From Aristotle to Darwin and Back Again: A Journey in Final Causality, Species, and Evolution (San Francisco: Ignatius Press).

Glennan, S. (2010) 'Mechanisms, Causes, and the Layered Model of the World', Philosophy and Phenomenological Research 81(2): 362-81.

(2016) 'Mechanisms and Mechanical Philosophy', in P. Humphreys (ed.) The Oxford Handbook of Philosophy of Science (Oxford: Oxford University Press): 796-816. 


\section{Daniel D. De Haan}

Hacker, P. M. S. and Bennett, M. R. (2003) Philosophical Foundations of Neuroscience (Malden, MA: Blackwell Publishing).

Hornsby, J. (2000) 'Personal and Sub-personal: A Defence of Dennett's Early Distinction', Philosophical Explorations 3(1): 6-24.

Illari, P. (2013) 'Mechanistic Explanation: Integrating the Ontic and Epistemic', Erkenntnis 78(2): 237-55.

Jaworski, W. (2011) Philosophy of Mind: A Comprehensive Introduction (Malden, MA: Wiley-Blackwell).

- (2016) Structure and the Metaphysics of Mind: How Hylomorphism Solves the Mind-Body Problem (Oxford: Oxford University Press).

Koons, R. (2014) 'Staunch vs. Faint-hearted Hylomorphism', Res Philosophica 91(2): 151-77.

(Forthcoming) 'Forms Are Not Structures But the Grounds of Structure: How Grounding Theory Illuminates Hylomorphism (and Vice Versa)'.

Lonergan, B. (1992) Insight: A Study of Human Understanding (Toronto: University of Toronto Press).

Machamer, P., Darden, L. and Craver, C. (2000) 'Thinking About Mechanisms', Philosophy of Science 67(1): 1-25.

Maley, C. and Piccinini, G. (2017) 'A Unified Mechanistic Account of Teleological Functions for Psychology and Neuroscience', in D. Kaplan (ed.) Explanation and Integration in Mind and Brain Science (Oxford: Oxford University Press): ch.11.

Marmodoro, A. (2013) 'Aristotle's Hylomorphism Without Reconditioning', Philosophical Inquiry 37(1/2): 5-22.

Marmodoro, A. and Page, B. (2016) 'Aquinas on Forms, Substances and Artifacts', Vivarium 54(1): 1-21.

McDowell, J. (1994) 'The Content of Perceptual Experience', The Philosophical Quarterly 44(175): 190-205.

Oderberg, D. (2007) Real Essentialism (London: Routledge).

- (2014) 'Is Form Structure?', in D. Novotny and L. Novak (eds.) NeoAristotelian Perspectives in Metaphysics (London: Routledge): 164-80.

Pasnau, R. (2004) 'Form, Substance, and Mechanism', Philosophical Review 113(1): 31-88.

- (2011) Metaphysical Themes 1274-1671 (Oxford: Oxford University Press).

Pemberton, J.M. (2011). 'Integrating mechanist and nomological machine ontologies to make sense of what-how-that evidence'.

http://personal.lse.ac.uk/pemberto

Ross, J. (2008) Thought and World: The Hidden Necessities (University of Notre Dame Press).

Salmon, W. (1984) Scientific Explanation and the Causal Structure of the World (Princeton: Princeton University Press).

Stump, E. (2012) 'Emergence, Causal Powers, and Aristotelianism in Metaphysics', in R. Groff and J. Greco (eds.) Powers and Capacities in Philosophy: The New Aristotelianism (London: Routledge): 48-68.

Tabery, J., Piotrowska, M. and Darden, L. (2017) 'Molecular Biology', in E. N. Zalta (ed.) The Stanford Encyclopedia of Philosophy (Spring 2017), at https://plato. stanford.edu/archives/spr2017/entries/molecular-biology/ [last accessed 10.4.17].

Wimsatt, W. C. (1997) 'Aggregativity: Reductive Heuristics for Finding Emergence', Philosophy of Science 64(4): 372-84.

Wright, C. D. (2012) 'Mechanistic Explanation Without the Ontic Conception', European Journal of Philosophy of Science 2(3): 375-94. 